\title{
Predictive habitat model for deep gorgonians needs better resolution: Reply to Etnoyer \& Morgan
}

\author{
Anna Metaxas*, Tanya Bryan \\ Department of Oceanography, Dalhousie University, Halifax, Nova Scotia B3H 4J1, Canada
}

Etnoyer \& Morgan (2007, this volume) state that our recent study (Bryan \& Metaxas 2007) is 'causing concern among scientists and conservationists in the USA'. This was certainly not our intent. In fact, in the last paragraph of our study we acknowledge that 'the need to protect deep-water coral from human influences has become more obvious' and suggest that without the right tools 'corals may remain unknown and unprotected'. It is most important to note that ours and Etnoyer and Morgan's motivations are the same: a better understanding of coral distributions and the factors that regulate them, to more effectively manage these organisms.

Our study focused on using Ecological Niche Factor Analysis (ENFA)/Biomapper to predict locations of suitable (rather than unsuitable) habitat for Paragorgiidae and Primnoidae and 'to attempt to locate previously unknown areas of potentially high coral abundance, based on the suitability of the habitat' (see 'Introduction', Bryan \& Metaxas 2007). In our results, we suggest that, in the Alaskan region, suitable habitat for both Paragorgia and Primnoa was found throughout the Aleutian Islands and on many seamounts, and we agree with Heifetz (2002). For the BC-CA region, we proposed that suitable habitat for both families occurs along the shelf break and on seamounts, a suggestion also made in Etnoyer \& Morgan (2005) and Morgan et al. (2005). On the generated habitat suitability maps, we only showed suitable and unsuitable habitat, defined most conservatively because of the coarse resolution of the data (see 'Methods', Bryan \& Metaxas 2007). Because of this coarse distinction that did not allow for the quantification of relative 'unsuitability', we only focused our presentation on suitable habitat. We never argued that continental shelves are not suitable habitat for coral (see Fig. 3 of Bryan \& Metaxas 2007 for data); however, we did argue that the shelf break and seamounts are.
It is widely accepted that the predictions of a model are only as good as the data that were used as input. Ours is no exception. We were faced with several challenges during our study: (1) no 'absence' data were available; (2) coral observations were limited in number and geographic extent; and (3) resolution of available data varied between environmental factors. These were discussed and/or addressed in our paper: (1) we selected Biomapper because it allows the use of 'presence only' data; (2) we conducted sensitivity analyses to address the effect of sample size on model predictions; and (3) all environmental factors had to be resolved to a common degree (and, thus, we could not use a higher resolution for bathymetry/slope than for current velocity or temperature), and we identified a grid resolution that we considered an acceptable compromise. We also conducted sensitivity analyses to address the effect of grid resolution on model predictions, and concluded that the most reliable approach is to limit the amount of data interpolation. This poses an important limitation on our current ability to predict suitable habitat (as described in the 'Discussion', Bryan \& Metaxas 2007), particularly with parameters such as substrate, which is currently very poorly sampled, but is also perhaps the most important factor in defining habitat suitability for deep-water corals.

Etnoyer \& Morgan (2007) list 5 weaknesses in Bryan $\&$ Metaxas (2007). Our responses to these (with specific references to the text of the latter study) are as follows: (1) Every parameter was not modeled (see Table 1). (2) The coarseness of the resolution is addressed above, and extensively discussed in the study (third and second last paragraphs in 'Discussion'). (3) Error was not discounted, but rather addressed quantitatively, using sensitivity analyses, and in several locations in the 'Discussion'. (4) The geographic extent of the analysis was selected based on maximizing the number of available coral observations, and thus the 
power of the predictions, while minimizing geographic cover. In the 'Discussion' (penultimate paragraph), we suggest that validation of the models by focusing on smaller geographic areas with higher resolution is in order. (5) Also in the 'Discussion' (penultimate paragraph), we identified ground-truthing of our predictions as an important next step. Obviously, this will entail major commitment by the research community (scientific and financial) and goes well beyond the scope of a single study or even a single researcher.

Etnoyer \& Morgan (2007) state that 'our predictive exercise failed to adapt to new information' and we 'rehashed an overly broad analysis', and refer to 2 other studies by us. To clarify the differences between the 3 studies, Leverette \& Metaxas (2005) did not examine gorgonian recruitment, growth and reproduction, as Etnoyer \& Morgan (2007) state. Rather, we used a previous and less reliable version of Biomapper to predict coral distribution on a narrower section of the Atlantic continental shelf. Bryan \& Metaxas (2006) described the environmental conditions at known locations of coral occurrence and explored whether they varied from the surrounding areas. Bryan \& Metaxas (2007) used the data described in Bryan \& Metaxas (2006) to generate the predictions by the latest version of Biomapper for both the Pacific and the Atlantic continental margins. We can only see complementarity among these studies.

In Bryan \& Metaxas (2007), we proposed that the continental shelf break and seamounts are locations with potentially high abundances of Paragorgia and Primnoa. We suggested that our predictions are only the first step in determining potential locations and discussed the limitations of the particular modeling exercise. Most importantly, we identified the current

Editorial responsibility: Lisa Levin (Contributing Editor), La Jolla, California, USA lack of relevant high-resolution environmental data as a major shortcoming in our ability to generate better predictions. We urged for the collection of such data, and it is our hope that our study will prompt such collections, to allow for more powerful analyses at higher resolutions. Informed decisions, which are based both on solid data and on quantitative analyses of these data, are imperative for the effective management of any species.

\section{LITERATURE CITED}

Bryan TL, Metaxas A (2006) Distribution of deep-water corals along the North American continental margins: relationships with environmental factors. Deep-Sea Res I 53: 1865-1879

Bryan TL, Metaxas A (2007) Predicting suitable habitat for deep-water gorgonian corals on the Atlantic and Pacific Continental Margins of North America. Mar Ecol Prog Ser 330:113-126

Etnoyer P, Morgan LE (2005) Habitat forming deep-sea corals in the Northeast Pacific Ocean. In: Freiwald A, Roberts JM (eds) Cold-water corals and ecosystems. Springer-Verlag, Heidelberg, p 331-343

Etnoyer P, Morgan LE (2007) Predictive habitat model for deep gorgonians needs better resolution: Comment on Bryan \& Metaxas (2007). Mar Ecol Prog Ser 339:311-312

Heifetz J (2002) Coral in Alaska: distribution, abundance, and species associations. Hydrobiologia 471:19-28

Leverette T, Metaxas A (2005) Predicting habitat for two species of deep-water coral on the Canadian Atlantic continental shelf and slope. In: Freiwald A, Roberts JM (eds) Cold-water corals and ecosystems. Springer-Verlag, Heidelberg, p 467-479

Morgan LE, Etnoyer P, Scholz AJ, Mertens M, Powell M (2005) Conservation and management implications of deep-sea coral and fishing effort distributions in the Northeast Pacific. In: Freiwald A, Roberts JM (eds) Coldwater corals and ecosystems. Springer-Verlag, Heidelberg, p 1171-1187

Submitted: March 24, 2007; Accepted: May 3, 2007

Proofs received from author(s): May 28, 2007 